\title{
Sober Ways, Politic Drifts and Amiable Persuasions; approaching the Information Highway from the Dusty Trail.
}

\author{
by Ken Hannigan ${ }^{1}$ \\ National Archives of Ireland
}

The term "National Archives" usually conveys an image of a large organisation with a staff numbering several thousands, as in the National Archives of Canada or the United States, or several hundreds, as in most of the national archives in Europe. It should be made clear from the outset, however, that the National Archives of Ireland must be considered on a much smaller scale. Ireland is a small country on the periphery of Europe with a small population (just over 3.5 million in the Republic of Ireland) and the National Archives of Ireland in Dublin can be seen to reflect the size of this population base. Not only are we smaller than most national archives, we are smaller even than the specialist divisions of many national archives. We are smaller, for instance, than the Center for Electronic records in the US National Archives.

Our total staff numbers 35; our total professional staff numbers 13 . We are, therefore, comparable in many ways to some of the state archives in the United States. In fact on the evidence of Richard Cox's recent study, The First Generation of Electronic Records Archivists in the United $\underline{\text { States, }}$ there are many points of similarity between the situation obtaining in state archives in the United States, and the situation obtaining both in the National Archives of Ireland and among the archival profession generally in Ireland. ${ }^{2}$

The National Archives of Ireland has existed under this name only since 1988 when the National Archives Act (1986) came into effect, though the constituent parts of our organisation, the State Paper Office and the Public Record Office of Ireland, have existed separately since 1702 and 1867 respectively and have been part of a de facto amalgamation since the late nineteenth century. The National Archives Act has radically transformed the role of our organisation, however, and has given us responsibilities similar to those of the National Archives of Canada and Australia. We now have a thirty year rule of access for government records, and no such documents may be disposed of without the written consent of the Director of the National Archives. Our Act placed an enormous burden on us, with accumulations of documents dating from the beginning of the state and before, and formerly not covered by legislation, having to be processed. At the same time as our responsibilities have expanded so dramatically, our traditional business has also been increasing significantly. We have an annual readership of 17,000. This may not be huge by the standards of most national archives (according to a recent notice posted on the "Archives" listserv, the number of people accessing the New York State Archives gopher in January 1995 was 17,000, the same as our readership for the whole of last year) but we have experienced a huge increase in public access in a generation amounting to a tenfold increase in the last twenty-three years.

Our user profile is very different to that of a data archives or library. Over 50\% of the readers' tickets which we issued in the first three months of this year were issued to people undertaking genealogical research on their own families. This statistic has a bearing on the sort of service we must provide and how priorities are addressed. Tourism is Ireland's second largest industry (after agriculture). There is a huge Irish diaspora in North America, Australia and the $\mathrm{UK}$, and it is from this that most of the tourist traffic comes. The roots factor is an important element in all of this and we are, whether or not we would wish to be so, part of the roots industry. Some $37 \%$ of our readers come from abroad, most of them tracing their roots, and they form a constituency which we must be careful to service.

Apart from genealogists, amateur and professional, the remainder of our readers are divided between academic researchers, local historians, teachers and trainee teachers, and a considerable body of legal searchers.

As to the documents being produced, the emphasis here is also heavily on genealogy. The household returns of the 1901 and 1911 censuses (which are, respectively, the earliest Irish census for which full household returns are extant, and the latest census for which the household returns are open to inspection) accounted for $42 \%$ of all documents produced to readers in the first quarter of this year. The 1901 census alone accounted for $26 \%$ of all documents produced in this period. Far behind the census, the next largest categories were:

$$
\begin{aligned}
& \text { modern departmental records }(22 \%) \\
& \text { eighteenth and nineteenth century State papers }(11 \%)
\end{aligned}
$$

and

$$
\text { testamentary records }(7 \%)
$$

Like most national or state archives, we must face two ways at once. We are expected to provide a service to a research 
public which is largely composed of genealogists, and we must provide a service to Government, to appraise its records which must be authorised for disposal or accepted for transfer. We must balance our obligations to the research public and to government with our obligations to a third constituency- posterity. We must preserve an adequate record of our own time and continue to preserve the records of previous ages which have been entrusted to our care.

We have 13 professional archivists on our staff. This is a small enough number, but in relative terms these 13 constitute a sizeable proportion of the professional body of archivists in Ireland. Total membership of that body at present numbers 67. Increasingly, candidates for jobs in archives are required to have a post-graduate qualification in archival studies. In the past twenty-five years archivists have professionalised, indeed it could be said that it is only in the last twenty five years that the profession has been defined in Ireland. Most current holders of the Diploma in Archival Studies are graduates of the only archives school in Ireland, that in University College Dublin, and so that school, to a large extent, controls entry to the profession. However, many of us in mid-career, particularly in the state sector, have no specialist archival qualification. We are all arts graduates, however, most with history degrees.

Because of our low numbers, there is no separate Irish professional organisation for archivists; we form an Irish region within the Society of Archivists, the bulk of whose members are in the United Kingdom. Our professional focus and contacts, therefore, have tended to be with our colleagues in the United Kingdom with whom we have much in common. And so to the dusty trail.

Dust is certainly a metaphor with which traditional archivists in Ireland and the UK are familiar, though not, perhaps, entirely comfortable. Dust and decay are an essential part of our popular image and this image is one of the problems which we face in approaching the superhighway. It is likely that a word association test administered to the average person in the street in Ireland would result in a string such as "archives, dust, decay, dead, buried". "Buried in the Archives" is a phrase we frequently hear used in relation to documents, or even in relation to ourselves as archivists! Thus the following statement which a national daily newspaper in Ireland recently published as part of an interview with one of the country's leading popular composers is probably fairly representative of popular attitudes:

"I honestly do believe that merely sticking with the past is for archivists. Forging new forms for the future, on the other hand, is for the living". 3

Well, certainly there is a sense in which archivists are seen to be, if not actually dead, then as having escaped from life. We hear frequent reports of people being told by career guidance counsellors or teachers that a career in archives is an option for those of a shy retiring nature, or timid disposition, who might find an alternative, teaching, for instance, or career guidance counselling, perhaps, too hard on the nerves.

We tend to have a cobweb-enshrouded image largely based (as Richard Kesner has identified it) on the popular notion that archivists are antiquarians, that we are a little removed from everyday life. ${ }^{4}$ We are not entirely blameless in this regard. Some of us have cultivated the image of the antiquarian, perhaps many of us are attracted by this selfimage and have even been attracted to the profession by it. So there may be something of a self-fulfilling prophesy at work here, as the world of traditional archives has attracted those who have consciously not wanted to be part of a thrusting, aggressive, brash, profiteering, macho world. We are mostly history graduates; we are people who put posterity above profit and power.

The world of archives is also a very stable one. Within the archival profession in Ireland today most us who have been there for ten years or more are doing the same jobs which we were doing ten years ago -and in the same organisations. Few of us have experienced anything else in our professional lives. It is not typical of the organisations with which we do business, the organisations for whose records we are responsible. It is certainly not typical of the IT people with whom we come in contact but who disappear out of our orbit again with bewildering speed. This stability has left many of us locked into practices and perspectives which are antidynamic. And as most of us are burdened by the daily demands of keeping a public service going and overwhelmed by backlogs of unlisted and unappraised records, it is frequently not until systems break down that we consider change.

There is a large element of this present in our response to computers. There was a time, not so long ago, when archivists could get away with a statement like "I know nothing about computers" and even make this sound like a virtue. We were helped in this by the fact that our favourite constituency of readers - historians -by and large also tended to spurn computers. It is of course no longer fashionable for archivists to admit that they know nothing about computers. Even the most obdurately antiquarian of us have by now realised that computers are, or should be, essential tools of the trade. But we are not yet really at home with them. We have not as a profession come fully to terms with the impact of automation. It is a fact that the largest special interest group within the Society of Archivists is the IT Group, but within that group to date we have tended to concentrate very narrowly on a single aspect of computerisation, and the most popular events organised by that group are software demonstrations. We are terribly interested in learning how computers can help us to continue doing the things we have always done in the ways we have always known and loved. We have come to the conclusion that computers are probably a good thing, we certainly want to know a little more about them, but really, we are not technical people and we still tend 
to revel a little in the fact. These attitudes put us at a considerable disadvantage in coming to terms with the wider aspects of computerisation.

Automation has implications for the specialised functions of "traditional" archives in three main areas.

Firstly there is the question of automating the archival tasks, accessioning, repository management, and so on. This should not pose any difficulties for traditional archives. We are basically talking about stock control here, something which is eminently suited to automation.

Secondly there is the obligation to provide an efficient and reliable service to readers and potential researchers, including the obligation to provide and disseminate information about our holdings. We are in the information business, though we do not all see it this way, and computers are tools for information management.

Thirdly there is the increasingly worrying question of what to do about the records generated by computers. These three aspects cannot be divorced; our failure to come to terms with the first two leaves us ill-equipped to deal with the third.

Many people from outside the world of archives, and even some archivists, are surprised at the failure of archives in Europe to automate more rapidly. In a recent issue of The American Archivist, Ronald Weissman expressed astonishment at finding a newly-created series of handwritten finding aids at the new State Archives in Florence $^{5}$. There would be no difficulty in finding similar instances of archives all over Ireland and the UK tenaciously holding on to the old methods.

There are two main problems which we face in automating and which partly, though not totally, explain our slow progress. One is quite simply the question of resources. It seems that archives everywhere are low on the priorities of governments and funding agencies. The country will not grind to a halt if the archives fail to function efficiently. The business of archival management does not generally attract large- scale commitment of resources. Our very modest degree of computerisation in the National Archives of Ireland has been achieved in a piecemeal manner and without the benefit of a specialist IT unit.

The second problem attaching to automation is potentially more difficult to resolve. Effective automation of archives demands consistent descriptive standards, ideally ones which are universally accepted. Unfavourable comparisons are frequently made between the extent of our computerisation and that obtaining in even fairly modest county libraries where users see the benefits of online catalogues and barcoding systems. There are of course some fundamental differences between archives and libraries, though these are not perceived by an impatient public, despite the efforts of both the professional librarians and professional archivists to delineate the two professions. The fact that our collections come ready- made, that rather than being a continuous series of single-level items our collections sometimes involve complex arrangements, and that retention or recreation of the original order is a cardinal rule of archival description, these have all posed problems for traditional archives the world over in their attempts to computerise their services and exchange information on their holdings. Despite some heroic, some would say quixotic, efforts, there is no universally accepted standard of archival description in Europe or even within the Society of Archivists in the UK and Ireland, nor is there any widely-used or agreed software for archives such as the Dynix system for libraries. To computerise the archives is to plough a lonelier furrow.

There have undoubtedly been some fairly sophisticated archival automation systems in Europe. The Public Record Office in London has since the nineteen seventies operated a computerised ordering system which is still far ahead of what is available in most other archives in Ireland or the United Kingdom. The current updating and extension of that system will put the PRO very much ahead of the field again. In France, computerisation allows not only for online searching of finding aids but also for remote access and advance ordering, something which is made possible by widespread use of the Minitel videotext system in that country, a degree of use unparalleled in any other European country (France's Minitel system accounted for $87.41 \%$ of all European videotext terminals in 1993) ${ }^{6}$. The Historical Archives of the European Union in Florence has, since 1993, provided online access to its database finding aids on the European Commission's Echo co-host. Spain is also well advanced towards linking its various state archives in one network which will allow remote access to all of them ${ }^{7}$.

Online access to finding aids is still very much the exception rather than the rule for European archives, however, and most computer- based projects have tended to be exclusive to each institution. There has been little or no co-ordination among or between archives, no sharing of information other than what is already available over publicly accessible channels, no cross-fertilisation. The systems are mostly not compatible with each other and do not lend themselves to the sort of inter-institutional exchange of information that is now the norm for libraries ${ }^{8}$. There is a commitment at high level to do something Europe-wide about automation and there is in existence a group of experts, comprising the heads of all national archives in the European Union, charged with coordinating archival policy and practice including archival automation, but a large part of the problem is that the senior managers, the heads of archives, who are attempting to formulate common policies in this area, are in general themselves not terribly comfortable with technology and, therefore, not sure what it is they wish to do. Despite a commitment to harmonisation and co-operation at the top, there has been little contact or co-operation among archives 
and archivists further down the hierarchy across national and linguistic boundaries.

A major part of the problem in Europe is also of course the difficulty of language. One indication of this is evident on the Internet. The archives listservs in North America are not parallelled in Europe (though a small "Archives and the Internet" discussion group has just this year been established within the IT group of the Society of Archivists in the UK and Ireland and may develop into a listserv. [Author's note:since this paper was presented, the "Archives and the Internet" discussion group has become a very vigorous forum for exchange of information among archivists in the UK and Ireland.]). While there has been criticism of the American "Archives" listserv from within the profession in the United States, it represents a very useful forum of over 2000 archivists exchanging information on matters of common concern. The US and Canadian listservs are certainly of considerable benefit to those of us who access them from outside North America. It is significant, though perfectly understandable, that those subscribers to the listservs who are outside the United States and Canada are mainly in the English speaking world, and predominantly in Australia and New Zealand. On the "Archives" listserv there are, for instance, only two subscribers from Germany (the country which accounts for $28 \%$ of the IT market in Europe) and none from France which, in terms of archival automation, is arguably the most advanced of the larger countries in Europe ${ }^{9}$.

It is obvious that the Internet as a whole is still overwhelmingly a North American phenomenon. But this area is developing rapidly in the UK and Ireland. In Europe the number of computers directly accessible on the Internet has doubled every year for the last three years, but in Ireland within the last year, the number has tripled, and all the signs are that this is continuing to mushroom ${ }^{10}$. The tendency until now within Ireland and the UK has been for Internet access to come mainly from the academic community. It is not common for government employees to have access to the Internet as part of their work, so there is no ".gov" element in our addresses. High telephone charges in Europe compared to those in the United States and the disparate nature of the telephone systems, which have coincided fairly rigidly with national boundaries, have inhibited access to the Internet by private individuals. Also household computer ownership in Europe is only about a third of that obtaining in the United States $^{11}$. Nevertheless, just by looking around one can see that things are changing. The fact that the next version of Microsoft Windows will come bundled with an Internet access program (Microsoft itself functioning as an internet access provider) will almost certainly result in a huge new wave of Irish and UK connections from outside academia. For those archivists who connect, there will probably be a gravitational pull, at least initially, towards North America rather than into Europe. Despite commitments to further cooperation and harmonisation in Europe, it is likely that the real dynamic will exist, for the moment, on the Internet.
Given that there has been no listserv for archivists in the UK and Ireland, presence on the American "Archives" listserv is probably a reasonable guide to the number of archivists who are using the Internet in these countries, and the number of archivists who are on the Internet in these countries is probably in turn something of an indicator of the extent to which archivists have themselves embraced the new technologies [Author's note:since this paper was presented, the "Archives and the Internet" discussion group has become a very vigorous forum for exchange of information among archivists in the UK and Ireland.]. Relative to the size of their populations, Australia and New Zealand are leagues ahead of the UK, and Ireland hardly figures. In this context it may also be significant that more than half of those appearing on the "Archives" listserv with UK addresses are in university archives rather than state or official archives.

The internet has huge potential for satisfying one of our primary needs, the need to disseminate information on our services and holdings to potential readers, and particularly to that diaspora of roots enthusiasts which we must cultivate. Some traditional archives have already started to run gophers or to put up Web pages. Although our own computerisation is not very far advanced, we have considered it important to establish a presence on the Internet and now have some pages on the World Wide Web by courtesy of a neighbouring third level college which has kindly afforded us space on their server ${ }^{12}$. There is clearly going to be growing demand for us to provide more and more information online. There will be growing pressure from Europe to service a free information market to match that being developed in the United States. Academics will surely soon start demanding that we use the available resources to improve access for them. It is rather surprising that they have been so reticent to date. In the light of the statistic of 17,000 people accessing SARA's gopher in January this year, we await with some trepidation the consequences of our own heads appearing above the parapet of the superhighway.

As "traditional" archivists, we have much to learn from the pool of available knowledge on the Internet in many areas, but particularly in relation to the problem of electronic records, which represents one of our greatest challenges, if not our greatest challenge, but has as yet has caused very few ripples to appear on the surface of the archival waters in Europe.

We in Ireland have a National Archives Act as strong as most comparable archives acts and one which gives us statutory powers in respect of digital data. Our Act specifically defines "Departmental records" to include magnetic tapes and discs, optical or video disks, and other machine-readable records. In fact there has been some debate over whether our Act, in specifying types of media, such as tapes and disks, has rather missed the point and concentrated on the medium rather than the message (a major part of the problem being of course that you can happily preserve mountains of disks and tapes but this will 
not guarantee that the data remain accessible). However, we are confident that such definition is not exclusive and we regard the terms "files" and "other documentary or processed material" mentioned in our act to be mediatransparent. It is the message that we are charged with preserving.

The main problem however, is not one of definition, it is the problem of what we do to give effect to our Act. We have not yet managed to seriously address the challenge posed by electronic records, but we are not alone in this regard. Although traditional archives in Europe are aware of the challenge posed by digital data, progress to date in addressing it has been very slow. According to a recent study presented to the Canberra conference on electronic records last November, no national archives in Europe has yet got beyond the stage of holding the output of anything other than database systems, and many of us have not even got that far $^{13}$. In the United Kingdom and Ireland the strongest player on the archival field and therefore the one that leads the way in many respects, the Public Record Office in London, despite a number of high level studies of the issue going back over twenty five years, has yet to decide a policy on electronic records ${ }^{14}$. Things now seem to be moving in Britain, however, with the appointment in late April 1995 of an Information Manager in the Public Record Office specifically charged with the task of developing a strategy for handling electronic records, and the appointment of a powerful committee of senior officials to ensure that he functions with the necessary support. It also seems certain that a formal decision will be made that archival electronic records in the form of structured datasets will be lodged with an existing agency rather than in the Public Record Office itself and that preservation of digital data will continue to be outsourced $^{15}$. In fact the existence of the ESRC Data Archive in Essex as the de facto place of deposit for official electronic archives in the United Kingdom has probably allowed the Public Record Office the luxury of time on this issue. Most of the large datasets which might have been identified for preservation by the Public Record Office have probably been preserved in Essex.

Elsewhere in Europe surprisingly little has yet been achieved. Per Nielsen has outlined exciting developments in Denmark which may offer a blueprint for some other countries $^{16}$. Of the other National Archives in the European Union, it seems that only those in Finland, France, Germany and Sweden have themselves accessioned electronic records and these mostly consist of datasets ${ }^{17}$. The National Archives of the Netherlands, however, has taken the initiative in attempting to bring the question of electronic records onto the archival agenda in Europe ${ }^{18}$.

Traditional archives seem to have suffered a paralysis in confronting this issue which has presented them with problems of two types. Firstly there are obvious problems associated with the preservation and future accessibility of such records - instability of storage media necessitating regular migration of data, rapid hardware and software obsolescence. There is no need to recite these to an audience of data archivists. It is possible that we in Ireland have already lost some of the large datasets created in our large information-gathering departments. We do not know, and our very preliminary efforts to find out, based as they are on our own ignorance of systems, have been inconclusive to say the least. The responses we have received have tended to be blandly reassuring, disturbingly so in the context of what we know to be the practice of some of these agencies in relation to their paper records. Given that we do not yet know how we are going to address this problem, we have not yet probed too deeply. That said, we have found the level of response to our preliminary questionnaires to be disappointingly low, the lack of response indicating, perhaps, a belief among IT managers that we are not there to help them.

The second area of concern for traditional archives relates more to what has been termed the second generation of electronic records, the records of the electronic office, and to what has been called the distributed environment in which electronic records are being created. Alongside the spread of computers has gone the breakdown of central file registries and filing systems. Everyone creates their own documents and files them on the hard drives of their PCs or on personal directories or even on floppies. We find a multiplicity of systems, a multiplicity of software packages being used on them, a multiplicity of drafts and duplicates being stored in them. Finding our way through this maze will be a colossal task.

The traditional practice of traditional archivists, appraising records when the records have reached the end of their lifecycle is clearly not appropriate in the case of electronic records. If we wait until the records cease to be current or until they are released into the public domain in thirty years, or even twenty years, time there may be nothing left to appraise. There is a coincidence of developments here which is alarming. The last twenty five years or so, a period which has seen and is continuing to see the transition from paper to digital records, is also the period which has seen a generation of archivists professionalise. We are in the process of climbing into our professional fortresses and pulling up the drawbridges behind us, making it more difficult for those from other than a very narrow spectrum of training to enter the profession. But it is ironic that this generation of archivists, which has been so careful to professionalise, to define standards, may be the generation which will fail most spectacularly to leave behind a record of its own time.

The options for traditional archives faced by the problem of what to do about electronic records are threefold. We can decide to use existing data archives and libraries as places of deposit and even perhaps develop an organisational link with these archives along Danish lines; we can try to establish our own data archives as an integral part of the existing archives; 
or we can insist that archival electronic records be maintained by the creating agencies, with our organisations providing an inspectorate to ensure that such records are adequately catered for by the creating agency. It is unlikely that the deposit of official digital data with an existing data archives will be the strategy followed in Ireland, despite the fact that this seems to be about to happen in the United Kingdom. There are various reasons why this is unlikely to be our route but the strongest one is that there is no such entity as a data archives currently existing in Ireland. As to our becoming a data archives, it has to be asked, and it has been asked, if it is at all appropriate for "traditional" archives to accession electronic records other than as a last resort? Would we be placing ourselves on a treadwheel to maintain access to these records, something which may be done only by relegating other aspects of our responsibilities? Would the archives be able to administer whatever privacy laws may regulate access to such data in the future? With so many systems current throughout the organisations for whose records we are ultimately responsible, would we have to become museums of software and hardware systems? The last question scarcely bears thinking about. As it is, we "traditional" archivists can barely master our own software and hardware.

There is a compelling logic to the arguments advanced by David Bearman and Margaret Hedstrom in favour of a noncustodial approach by traditional archives to such records ${ }^{19}$. The fact that the Australian Archives will now opt for this kind of approach, as set out in recently published guidelines, will weigh heavily in its favour with those of us who have yet to make a decision in this area ${ }^{20}$. This question will be addressed at European level in the Spring of 1996 when a major multidisciplinary forum will be called in Brussels to be attended by representatives of archives as well as IT specialists from throughout the European Union. This meeting will be held under the auspices of the European Commission and will attempt to co-ordinate policy on machine readable records. It seems very likely that this forum will be influenced by decisions taken by the Australians and by the very forceful arguments emanating from Pittsburgh.

Yet there is a huge caveat which must be entered here, as Edward Higgs has recently warned elsewhere ${ }^{21}$; our previous experiences with some of the agencies which would have to become custodians of archival data do not inspire total confidence. Yet it seems at the moment that, even with this caveat, local retention is the only practical option open to us in Ireland - though this of course may change. As mentioned above, traditional archivists in Ireland are not computer people. We in the National Archives do not at present have the resources to manage these records. It is unlikely that we will be given them in the short term, not on the sort of scale that would make the job feasible, and there is little merit in embarking an a project with a better than even chance of failure.
It is simply very difficult to force the issue of electronic records onto the archival agenda or indeed onto any agenda. Few people are interested. There is no pressure group or no constituency outside the archives demanding that something to be done about electronic records.

Historians in Ireland have not seriously begun to use such records (some of them are now engaged in setting up databases of economic statistics or even online textual databases, but they have not yet begun to lobby on behalf of existing machine readable records). The late John Blackwell who addressed the Amsterdam conference of IASSIST in 1985 made some attempts to raise the issue in Ireland, but seems to have met with little support ${ }^{22}$. If we were to close our reading room in order to stocktake, were we to withdraw a heavily used series of records and substitute microfilms, we could be fairly sure of a loud and unfavourable reaction from our research public. But if we choose to do something which will actually result in catastrophic consequences, if we ignore electronic records, no one will notice for a long time. No one outside the world of archives is currently lobbying about electronic records. This is something that we in the archives have to worry about for the moment on our own, sure in the knowledge that if we continue doing nothing will have left a shameful legacy.

We must seek allies in attempting to give electronic record keeping a higher priority. There are some developments which indicate where we might find these allies. Freedom of Information legislation is imminent in Ireland. There is a strong political commitment to this at present and the legislation currently promised looks set to be a far-reaching measure with radical effect. There will be major consequences both for the archives and for the holders of official information. For the archives, Freedom of Information, together with Data Protection, may eventually supplant the National Archives Act and the 30 year rule as the regulator of access. There are, anyway, moves in Europe to have the norm for access reduced to twenty five or twenty years ${ }^{23}$. The gap, therefore, between current records and noncurrent records is likely to diminish. As for the informationcreating agencies, they will have to be more accountable for the information they create and hold, in whatever form it is held. Something like the traditional registry system will have to be reinstated, but perhaps with routes of access from the outside world. And this system will of course have to encompass electronic records. Perhaps a Government Information Locator System may be used in the future as a route into unpublished official information or archival information, or at least into the finding aids for such information, and may ultimately support a gateway for online access to archival electronic records.

Whether traditional archives become non-custodial regulators of electronic records or custodians of such records, or, more likely, become a combination of both, we will clearly have to acquire the knowledge and skills which will allow us to make intelligent and correct decisions on the 
scheduling of such records. Given our background and training and what has been to date an unimpressive track record with computers, it is unlikely that we traditional archivists will easily turn ourselves into electronic archivists. No-where within the profession in Ireland at the moment are there the skills required to tackle this job. We are, however, greatly heartened by the news that one of the staff of the Center for Electronic Records at NARA, Mark Conrad, has been selected under the Fulbright scheme to spend the next academic year teaching in the Archives Department of University College Dublin. This is a hugely significant development in terms of archival formation in Ireland and we may soon see the emergence of a generation of Irish archivists with some skills in the management of electronic records. Perhaps we in the traditional archives also need to make more radical plans now for a period of transition, and look outside our traditional recruiting pool to train new archivists for a new age. We should, to the extent that we can, encourage into the profession some from a technical rather than an arts background. And certainly "traditional" archivists must seek to forge stronger links with the data archivists and librarians, for it seems that we are now on the same road, having travelled to it from very different starting points.

1 Paper presented at IASSIST 21st Annual Conference May 9-12, 1995, Quebec City, Canada.

2 Richard Cox, The First Generation of Electronic Records Archivists in the United States: A Study in

Professionalization (Primary Sources and Original Works, Volume 3, Numbers 3/4), (New York, 1994).

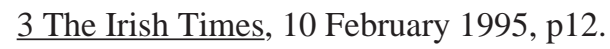

4 Quoted in Cox, op. cit., p.40

5 Ronald F.E. Weissman, "Archives and the New Information Architecture of the late 1990s" in The American Archivist, Vol 57, Winter 1994, pp 20 -34.

6 Emerging Technologies: Information Networks and the European Union (European Parliament, Directorate General for Research, Working Papers, Economic Series Wll), (Luxembourg, 1993)

7 Archives in the European Union (Report of the Group of Experts on the Coordination of Archives), (Luxembourg, 1994).

8 ibid.

9 List of subscribers to "Archives" and "Arcan-L" listservs supplied on 26 and 28 April 1995.

10 Communications Today, Vol. 2, No. 2, (Dublin, March 1995), pp 22-23.

\section{Emerging Technologies, p.5}

12 The address for the National Archives of Ireland Home Page at the Dublin Institute of Technology is <http:// 147.252.133.152/nat-arch/>.

13 Edward Higgs, "Information Highways or Quiet Country Lanes? Accessing Electronic Archives in the United Kingdom", paper read to the "Playing for Keeps" conference on electronic records held in Canberra, Australia, 8 -10 November 1994.

14 ibid.

15 Unpublished lecture by Alexandra Nicol delivered to the IT Group of the Society of Archivists, at the Public Record Office, Kew, London, 30 March 1995.

16 See Per Nielsen, "Merging Cultures: Danish Integration of Academic Data Services into a Traditional Archival System" elsewhere in this volume.

\section{Higgs, op cit.}

18 T. K. Bikson and E. J. Frinking, Preserving the Present: Towards Viable Electronic Records, (The Hague, 1993).

19 For a discussion of these arguments see especially David Bearman and Margaret Hedstrom, "Reinventing Archives for Electronic Records: Alternative Service Delivery Options" in Electronic Records Management Program Strategies (Archives and Museum Informatics Technical Report No. 18), (Pittsburgh, 1993).

20 Greg O'Shea, Managing Electronic Records: a Shared Responsibility (Canberra, 1995).

21 Higgs, "Information Highways"

22 John Blackwell, Information for Policy (National Economic and Social Council Report, No. 78), (Dublin, 1985) pp. 105-107. John Blackwell, "Public Data in Use: a Case Study of Ireland", IASSIST Quarterly, Fall/Winter 1985, pp. 3-13.

23 Archives in the European Union (Report of the Group of Experts on the Coordination of Archives), (Luxembourg, 1994). 